Some Developments in Oblique Aerial Photography as Applied to Forest Surveying in Canada.

S.N. Cooper。

Introduction.

The work of the Topographical Survey Branch of the Department of the Interior in its preparation of topographic maps compiled from oblique aerial photographs is well known. These maps are in daily use by prospectors, lumbormen, trap pers, aviators, tourists and others, and all attest their accuracy and completeness in detail.

Little use, however, has been made of oblique aerial photographs in the making of timber type maps as a step in tho carrying out of extensive forest surveys.

There are numerous instances of type maps having been made from vertical photographs. The method has many advantages over that in which oblique photographs are used, but without going into the advantages and disadvantages of the two methods, it is obvious that the cost factor alone weighs heavily in favour of oblique photography in certain types of country and where the survey is to be of an extensive nature.

It is not proposed here to go into the many details which enter into the taking of oblique photographs; the construction of plotting grids; the compilation of the plots from the photographs by means of grids and the final assembling of the plots to make the final type or topographic map.

The purpose of the paper is to show by means of a concrete example how oblique aerial photographs may be used in the carrying out of an extensive forest survey. The methods employed here have their limitations and there are modifications which might have been introduced to advantage. These also may be brought out.

The example in particular is that of the survey of roughly 25,000 square miles of timberland in Manitoba, from which territory the Nanitoba Paper Company will draw its pulpwood supply. The survey was conducted by the Dominion Forest Service in conjunction with the Manitoba Paper Company. It was imperative that the survey be completed in one year, so that time became a factor of almost greater importance than cost.

The Topographical Survey of Canada had already compiled topographic maps of parts of Nanitoba, and it was only by extending this photographic work over the area under examination 
and by preparing topographic and type maps, that the completion of the survey during the same season was made possible.

It is to this survey that reference is made throughout this paper and from which some conclusions may be drawn. Acknowledgment is here made to the Dominion Forest Service and the Topographical Survey of Canada, with the explanation that any criticism made is intended to be of a constructive nature and is purely the result of experience gained on this survey.

\section{The Area.}

One of the first considerations when contemplating the use of aerial photography in forest surveying is the relief of the country. Obviously a country with a mature topography lends itself more readily to photographic work than will a more youthful topography. This is more particularly true of oblique than vertical aerial photography. Both vertical and oblique aerial photography may be applied to a country of mature topography; both have their merits; but one of the requisites of oblique photography is that the country be one of low relief.

In this instance we have a type of country which fills all the requirements of oblique photography - a country of very low relief, lying at the western extremity of the Laurentian Plateau. Elevations range from 715 feet at Lake Winnipeg to about 1015 feet at the Ontario-Manitoba boundary line, a very gradual fall of about 300 feet in 80 miles. It is a country of many streams and lakes - lakes ranging in size from a few acres to 50 square miles or more. It is a country over most of which seaplanes or flying boats may fly at altitudes as low as 2500 feet with reasonable certainty of reaching water in case of engine trouble.

Apart from these facts, two conditions made it almost imperative that planes be employed:- Firstly, about 75 percent of the area under examination is waste. Merchantable timber is, for the most part, confined to the better drained sites bordering streams and lakes. Between the streams lie vast expanses of treed and treeless muskeg; or, where better drained country is found, repeated forest fires have over large areas reduced that country to a soilless and barren condition.

It was essential, therefore, that these waste areas be located and their boundaries determined, at as low cost as possible, in order to eliminate them in laying out the work of ground parties.

Secondly, the area is unsurveyed; there is a total 
absence of land lines of any sort. Previous to the survey the existing maps showed only the approximate shape, size and position of the larger lakes, and only the general location of streams. Thousands of small lakes and streams were not shown on any map. There was, therefore, total absence of anything which might serve as controls for ground parties.

Plan of Survey.

Given the above stated conditions, it may be readily seen that aerial photographs can supply:-

1. Data with which to compile topographic maps of sufficient accuracy for the purpose needed.

2. A control in the shape of streams and lake shores.

3. Data with which to compilo a map showing waste and timbered areas and possibly a further division of timbered areas into types, clesses or qualities.

The first two items will be generally accepted as true, but there will be some scepticism about the truth, or at any rate, the practicability of the third claim for the photographs.

There is no doubt whatever that badly burned-over country in which the bare rock is exposed, and also bog and treeless muskeg, can be identified even on comparatively poor photographs, but there are many and vast areas of muskeg bearing spruce and tamarac of varying degrees of density and in diameter ranging from an inch or less to merchantable size. Anyone familiar with the north country has seen muskegs in which there is a very gradual falling off in the size of the trees when passing from the outer edge towards the middle of the muskeg. The complete gradation from merchantable timber to scrub or no troes at all, may occur in a distance of a few chains or it may run into a mile or more. Somewhere in this muskeg a line must be drawn between merchantable timber and waste and it appears impossible to locate that line with any degree of accuracy on the general run of oblique photographs. It is a difficult matter for even an experienced aerial observer to locate that line from the air, as experience has shown. True, there are signs, such as wide spacing of trees, which may be used as an indication of muskeg conditions or poverty of growth for some other reason: but the fact remains that the distinction cannot be made on oblique aerial photographs with any certainty. The same applies to the identification of dense stands of reproduction which are of frequent occurrence in the Western Laurentian region. There appears to be no practical way of correcting this 
shortcoming. The use of nothing but the best photographs would help considerably, but ideal photographic conditions are not encountered very frequently in the course of the short northern suminer.

The omployment of a photographic compiler who is also a forester would tend to yield better results, but the combination may be hard to find, for the efficient compiler is usually an office worker, as was the case in the Manitoba survey. The best that can be done is to have all compilation done by one man; who will be, at any rate, consistent in his judgment, be it good or bad.

It is not imperative, of course, that any timber type distinctions be shown on the topographic sheets, but recent burns, burns not reproducing, grass swamps and treeless muskeg should certainly be shown, for their barren condition may be relied on, and if anything, they will bo of larger extent than is shown on the maps. be somewhat as follows:-

Given such maps, the procedure of ground parties will

Ground parties will be supplied with maps drawn on two scales - a small scale map for general use in planning the ground work and as a guide to the country; and a large scale map (two inches to the mile or whatever scale is preferred) on which strip lines will be drawn, and the field notes plotted.

Each ground party will be supplied with oblique aerial photographs of the territory assigned to it; a set of grids for use in plotting detail from the photographs; and a key map on which is shown the point at which each photograph was taken and the direction in which the camera pointed. By means of the photographs the cruiser will be ablo to supply his plan with type lines. and other details between strips, which information he would otherwise have to fill in by conjecture.

Provided that sufficient samples are secured, this advantage will permit the running of strips at wider intervals then would otherwise have been permissible. The cruiser may find himself in a country which, though not shown as waste on his base map, proves to be non-timbered, or at any rate, country in which he is not interested. Ho does not know the extent of this type and in the absence of photographs or other aerial help, he must continue to run strips through this type; but his photographs will show the extent of it and if it is apparent that the portion which he has seen is representative of the whole, then there is no occasion to spend further time on it.

Sufficient experience has been gained in the use of 
photographs for this purposo to claim for them the liklihood of a more accurate type map, and a very considerable speeding up of the ground work.

The maps supplied to ground parties may be modified to suit forest conditions, or the requirements of the survey. If the character of the forest and the quality of the photographs permit, the compiler may go one step further in his preparation of maps. He may construct from the photographs a type map, which, if reliable, leaves nothing to the ground parties beyond the sampling of the merchantable types and the checking of the type boundaries.

In the Manitoba Survey, five forest classes, in addition to swamp and bog, were observed.

\author{
1st. Good \\ 2nd. Good to Fair. \\ 3rd. Fair. \\ 4th. Poor. \\ 5th. Largely Barren.
}

The first three classes only received the consideration of the ground parties. Classes 4 and 5 represented treeless muskeg, burns not reproducing and burns and muskeg bearing trees in non-commercial quantities. These two classes together with swamps and bogs occupy more than $50 \%$ of the land area.

Since it was not possible to distinguish one softwood species from another on the photographs, no mention of species was made on the photographic maps. Classes 1,2 and 3 embraced all merchantable timber in commercial quantities.

The work of the ground parties consisted in sampling classes 1,2 and 3 (the sample strip system was used) and typing the timber with the aid of their photographs as described above.

If the classification of the timber, and the type or class boundaries, as shown on the photographic maps, had proved to be correct, then the experiment would have been an undisputed success. Unfortunately, oblique aerial photographs have their limitations and these can be brought out in reviewing the results of the survey.

Some Results of the Survey and Some Limitations.

Undoubtedly the greatest limitation is that of cost. But different systems of forest surveying have different functions, depending on the particular set of conditions to which they are to 
be applied and depending also on the purpose of the survey.

Let us see what was required in the Manitoba Survey;-

It was required to locate and estimate the quantity of pulpwood, presently exploitable, on a given area. Since aerial work of some sort was necessary in view of the time element and the necessity of eliminating the waste areas, it was essential that a base map be available - a map with sufficient known points to serve as a control for an aerial sketcher and for ground parties. That base map was not securod. The cost of the photographic work can - if not wholly, then in pert, be charged to the compilation of a topographic map, and not to the forest survey proper. If the cost of the survey is to be based on the quantity of wood estimated - which seoms a reasonable basis in this particular instance then the survey was one of extremely high cost. It can be said, then, that oblique aerial photography, under the physical conditions already described, has its place in a forest survey, only when the enterpriser is prepared to pay a fair price for a topographic map. This he mill not be prepared to do when the quantity of timber located is not commensurate with the high cost of the survey.

It is estimated that a map showing topography and timber types can be plotted from oblique aerial photographs at a cost of about sixty cents per squaro mile.

Assuming a charge for aircraft of $\$ 125.00$ per hour, the flying and photographic costs may renge from $\$ 1.00$ to $\$ 2.50$ per square mile, depending on weather conditions, the type of aircraft employed, the nature of the country and other factors.

On an area of 6,000 square miles the cost of the completed map should be under $\$ 3.00$ per square mile. On a greater area, the cost per square mile will be somewhat lower on account of the greater area over which to spread certain fixed charges; while for a smaller area the revorse will be the case.

It will be generally agreed that $\$ 3.00$ per square mile is a reasonable price to pay for a topographic and type map, as compared with the probable cost of such maps made by other means. But the fact remains that any cost is too great when the results achieved - in this case, the quantity of pulpwood located do not warrant such expenditure.

This, however, is not a condemnation of oblique aerial photography on the score of high cost; but is an indication that some preliminary investigative work is necessary to see if the system is applicable to the particular existing conditions. 
The second importent limitation lies in the difficulty in delineating type boundaries and in distinguishing mature from immature types, on the aerial photographs. There need be no a.t tempt made to distinguish merchantable types from one another that can be done from the ground - but where it is desired that ground parties focus their attention on merchantable timber the value of the photographic maps is very materially decreased when numerous and extensive areas of second growth softwood are represented to be merchantable timber.

Such was the case in the Manitoba Survey. It is safe to say that 25 percent of the time of ground parties was lost in examing what proved to be either muskeg, bearing small, stunted spruce and tamarac, or burned over country bearing dense reproduction of softwood species.

\section{Recommendations.}

No remedy is suggested here towards correcting this shortcoming in oblique aerial photographs, unless it be that better photographs be secured; but even with better photographs, there would still be cases where some uncertainty existed as to the accuracy of the photographic compiler's work, which contingency would still call for some sort of check on the photographic map.

Indeed a check is advisable in any event; and the cheapest means of getting that check is from the air. An experienced aerial observer with the photographic maps in his possession could focus his attention on all areas shown on his maps as bearing merchantable timber, and where necessary make corrections. $\mathrm{He}$, of course, may make errors in judgment, too, but he will err, as a rule, on the side of classing immature timber as merchantable rather than the reverse, so that there will be little fear of merchantable timber being overlooked in the survey. It is believed that a big reduction in the cost of the ground work of the survey may be effected in this way, without detracting from one's confidence in the report of the survey. 